\title{
Complete paralytic botulism mimicking a deep coma in a child
}

\author{
Ebru Azapağası1 ${ }^{1}$, Tanıl Kendirli1 ${ }^{1}$, Gökçen Öz-Tuncer², Pelin Albayrak², Serap Teber², \\ Gülhis Deda ${ }^{2}$ \\ Departments of ${ }^{1}$ Pediatric Intensive Care Unit and ${ }^{2}$ Neurology, Ankara University Faculty of Medicine, Ankara, Turkey. \\ E-mail: ebruazapagasi@hotmail.com \\ Received: 17th February 2017, Revised: 30th April 2017, Accepted: 1st May 2017
}

\begin{abstract}
SUMMARY: Azapağası E, Kendirli T, Öz-Tuncer G, Albayrak P, Teber S, Deda G. Complete paralytic botulism mimicking a deep coma in a child. Turk J Pediatr 2017; 59: 581-585.

Botulism is a rare cause of neuroparalysis. Delay in diagnosis and treatment exerts adverse impact on mortality and morbidity. We report a child with complete flaccid paralysis followed by progression to coma-like consciousness. The patient required mechanical ventilation. As serological tests could not be performed, detailed history and physical examinations led to the suspicion of botulism, and repetitive nerve stimulation tests supported the diagnosis. Botulinum antitoxin was administered. The patient's neuromuscular function improved rapidly.
\end{abstract}

Key words: Clostridium botulinum, food-borne botulism, paralysis, coma.

Botulism is a rare intoxication, but can lead to severe neuroparalysis. Botulinum neurotoxins are produced mostly by Clostridium botulinum and more rarely by Clostridium butyricum and Clostridium baratii. ${ }^{1}$ Clostridium is a gram-positive anaerobe bacteria. Its toxin is extremely lethal. Estimated lethal dose is $1 \mathrm{ng} / \mathrm{kg}$ when toxin $\mathrm{A}$ is ingested orally. ${ }^{2}$ The incubation period of botulism is hypothesized to range between 3 and 30 days. ${ }^{3}$ The main types of toxin causing disease in humans are A, B, E, and F. Botulinum toxin irreversibly inhibits the release of acetylcholine from cholinergic ends of presynaptic and autonomous nerves at neuromuscular junctions. ${ }^{1}$

Four clinical types of botulism have been defined; food origin botulism, wound botulism, infant botulism, and adult intestinal toxemia botulism (a rare form of intestinal colonization and toxin production in adults). ${ }^{4}$ Botulism is characterized by symmetrical, acute and descendant flaccid paralysis arising in patients without fever, sensory deficit or loss of consciousness. Bulbar palsy (diplopia, dysphagia, dysarthria, dysphonia) and autonomous dysfunction (constipation, urinary retention, mydriasis, hypotension) are other clinical findings of the disease. $^{5}$
The administration of antitoxin in the early period is very important for treatment. ${ }^{2}$ Although the disease is rare, mortality may be as high as $40-50 \%$ in untreated cases ${ }^{5}$. In this report, we present a case referred with complete flaccid paralysis who was intubated within 24 hours and who improved rapidly with treatment although antitoxin was administered 5 days after the onset of symptoms.

\section{Case Report}

A 3.5-year-old boy had complaints of diplopia, followed by ptosis of the left eyelid two days before being referred to our hospital and was unable to walk one day later. The muscle strength score was 0 in all extremities and the patient was intubated. Guillain-Barré syndrome was considered in another hospital and intravenous immunoglobulin (IVIG) (0.4 $\mathrm{g} / \mathrm{kg} /$ day) was initiated. The patient had IVIG therapy for two days and a single dose of steroid and was transferred to our intensive care unit on the third day of hospitalization for further investigations and treatment.

Patient had no previous history of infection, fever, rash, animal-insect bite, trauma, drug or recent vaccination or travel. From the patient's 
history, it was learned that he was born at term weighing 3650 grams, had no problems after birth, his growth and development were normal, parents were not consanguine and there was no neurological disease in the family. The patient was admitted to ICU with poor general condition, unconsciousness and intubated.

On neurological examination, there was no response to vocal or painful stimulation. Spontaneous respiration was absent. Pupilla were isochoric and mydriatic. Light reflex was weak, cornea and oculocephalic reflexes could not be elicited. There was no facial asymmetry. Extremities were immobile and loose. Deep tendon reflexes could not be elicited. There was no nuchal rigidity and Glasgow Coma Scale was 3.

Blood count results performed after the patient was admitted were as follows: hemoglobin 12 $\mathrm{g} / \mathrm{dl}$, white blood cell $7,800 / \mathrm{mm}^{3}$, thrombocyte $347,000 / \mathrm{mm}^{3}$ and C-reactive protein was $<1 \mathrm{mg} / \mathrm{L}$. Creatine kinase level was normal. There were no cells observed on examination of cerebrospinal fluid (CSF). CSF protein and glucose were within normal range and viral-bacterial panel was negative, without any growth in cultures. Respiratory tract viral panel was negative. There was no growth in blood culture, while E.coli growth was seen in stool culture. Electrocardiography and chest X-ray were normal. In this unconscious patient EEG revealed encephalopathy with widespread slow wave activity. On cranial CT and MR imaging, no pathology was seen. There was no constipation. When the history

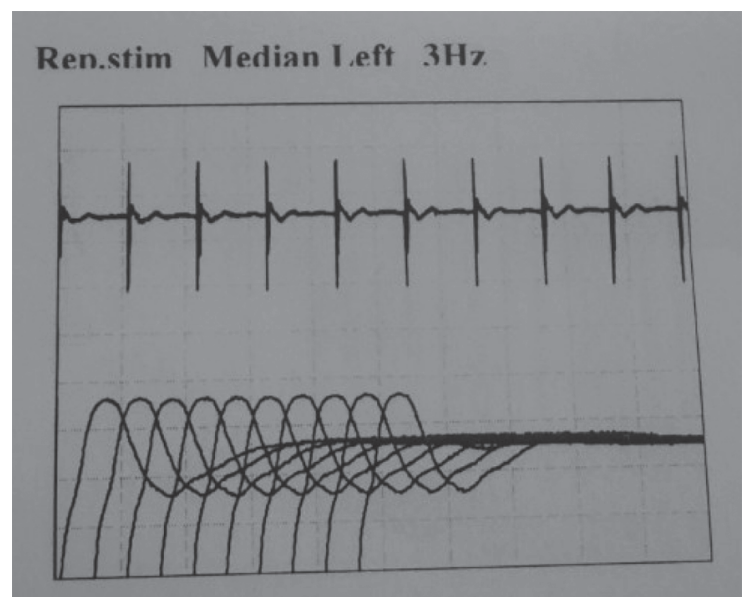

Fig. 1. No change in compound muscle action potential amplitude at 3 Hertz repetitive nerve stimulation. was detailed, it was learnt that two adults and a child living in the same district had similar complaints. Because of autonomic dysfunction he underwent electroneuromyography (ENMG) examination with the presumptive diagnosis of botulism. Sensory-motor nerve conduction and latency were normal. Repetitive nerve stimulation of median nerve was performed at $3 \mathrm{~Hz}$ and $20 \mathrm{~Hz}$. At $3 \mathrm{~Hz}$ stimulation; CMAP amplitude didn't change, but at $20 \mathrm{~Hz}$ stimulation an increment in the amplitude of CMAP was observed (Fig. 1, 2).

On 2nd day of admission, $500 \mathrm{ml}$ botulism antitoxin (A, B, E) was administered. Approximately 6 hours after the administration of antitoxin, spontaneous respiration started. On the third day of antitoxin treatment, patient started to nod in response to verbal stimulation. He was extubated on the 8th day of antitoxin treatment. Three days after extubation, patient was transferred to neurology inpatient clinic and was discharged without any sequels in the 3rd week of hospitalization. Case was notified to the Ministry of Health. There was no contaminated food determined.

Written consent for publication of this case report, accompanying images and videos was obtained from the parents of the patient.

\section{Discussion}

Botulism is mostly a consequence of intake of canned food prepared from vegetables, meat, fish and cheese at home. Clostridium botulinum spores are resistant to high temperature and can only be destroyed by 2-3 hours of boiling, although the toxin is sensitive to heat and

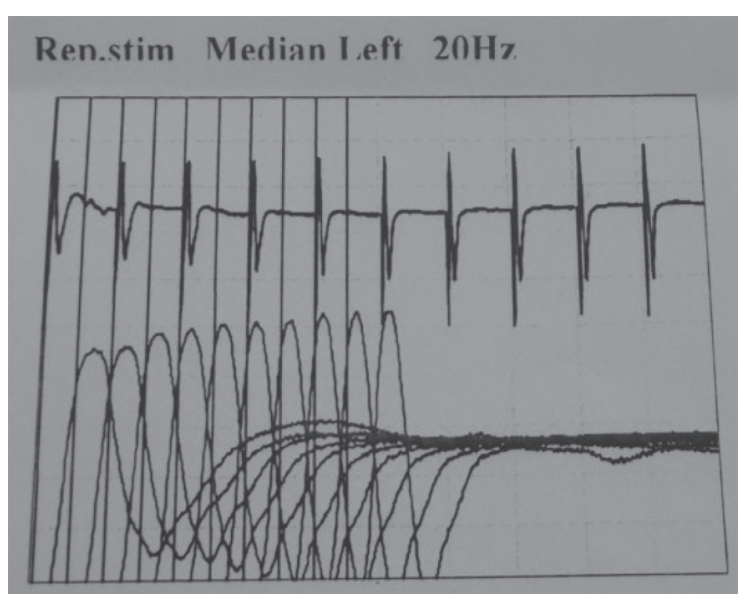

Fig. 2. Repetitive nerve stimulation at $20 \mathrm{~Hz}$ showed incremental response. 
denaturated with boiling for 10 minutes. In canned food which is not prepared and kept in proper conditions, bacteria may grow and produce toxins. ${ }^{6}$ In children, botulism associated with food intake is extremely rare. Botulism is a disease which occurs seldom all over the world. Approximately 110 cases are reported annually in the United States. Around $15 \%$ of the cases reported yearly in USA are those of food borne botulism. The mean number of cases was 17 from 2006 through 2010. The most common reported food sources are vegetables, fish, fruits, and condiments ${ }^{7}$.

Food botulism first affects ocular and oropharyngeal muscles 12-36 hours after the intake of toxin. Prodromal symptoms may be blurred vision, dysarthria and dysphagia. There is no fever. Fever is typically absent and might be an indication of a secondary bacterial infection or associated with wound infection or abscess formation in cases of wound botulism. ${ }^{7}$ It spreads by descending within four-five days and extends to extremities and respiratory muscles. Respiratory failure may appear gradually or suddenly and it occurs in $20-35 \%$ of patients. The mean duration of ventilator support is 7 weeks. ${ }^{8,9}$ Spread is symmetrical. In the majority of cases autonomic dysfunction symptoms such as mydriasis, weak light reflex, dry mouth, constipation, and urinary retention occur. Mental functions and senses remain normall, 2,5 because the toxin does not cross the blood-brain barrier. ${ }^{3}$

In differential diagnosis, other causes of acute flaccid paralysis, i.e. Guillain-Barré syndrome, Miller-Fisher syndrome, poliomyelitis, myasthenia gravis, paralysis associated with tick bite, stroke syndromes, toxic substance intake, acute motor axonal neuropathy, myopathies, acute transverse myelitis, and hypokalemic period paralysis were eliminated via history, imaging and electrophysiological studies and examination of CSF.6,7,9

Botulinum toxin is detected in serum or stool specimens in approximately $46 \%$ of clinically diagnosed cases. In foodborne cases, serum toxin assay may remain positive for maximum 16 days after admission. Stool cultures grow C. botulinum in around $70 \%$ of the cases. Even though the organism is more frequently detectable merely in the early stages of disease, it can remain in the stools for 5 months in patients with infant botulism. All specimens, especially blood specimens, should be taken as soon as possible after the diagnosis is suspected and prior to administration of the toxin. 3,7

The determination of botulism toxin was planned however, although the toxin can be demonstrated in serum, gastric secretions, vomitus and stool, diagnosis could not be confirmed in this manner as the toxin cannot be determined in our country.

EMG shows a distinctive pattern of brief, small-amplitude, overly abundant motor unit potentials $^{3,7}$. On ENMG, while $3 \mathrm{~Hz}$ was normal, at $20 \mathrm{~Hz}$ the incremental response to repetitive nerve stimulation made diagnosis more definite. ${ }^{4,6}$ Subsequently, 5 days after the onset of initial symptoms, the patient was given antitoxin treatment at 48th hour of admission. Following antitoxin treatment, findings regressed rapidly.

The basis of botulism treatment is close monitoring of the case and supportive treatment. The role of antimicrobial therapy in foodborne or the adult intestinal colonization form of botulism is not established. The administration of antitoxin in the early period is very important. In botulism associated with food intake, heptavalent antitoxin (A, B, E) treatment is used. $4,5,10,11$ Some research and expert consensus advocate the use of heptavalent antitoxin type A to $\mathrm{G}$ in non-infant botulism cases. ${ }^{7}$ Antitoxin stops the progress of paralysis, shortens its duration and decreases the need for mechanical ventilation. Botulinum antitoxin may be used within the first 24 hours after the onset of initial symptoms $4,5,10,11$. Higher rates of morbidity and mortality are associated with larger doses of ingested toxin and a shorter incubation period. Mortality is higher in type $\mathrm{A}$ than type $\mathrm{B}$ or $\mathrm{C}$ toxin disease. Timely identification of the index case in an disease outbreak may make the prognosis of other cases exposed to same food better. ${ }^{7}$

In a retrospective study with 134 patients who were diagnosed with type A botulism, the mortality rate was $10 \%$ in patients where the antitoxin was administered within 24 hours whereas the mortality rate was $15 \%$ when the antitoxin was given after 24 hours. The mortality rate was $46 \%$ in untreated patients. ${ }^{12,13}$ 
Table I. The Findings of Our Case and Other Cases in the Literature.

\begin{tabular}{|c|c|c|c|}
\hline Country & Turkey & Taiwan & Italy \\
\hline Age & 3.5 years & 4 years 8 months & 11 years \\
\hline Gender & Male & Male & Male \\
\hline Past medical history & Not significant & Not significant & Not significant \\
\hline Time of diagnosis & 4th day & 2nd day & 1st day \\
\hline $\begin{array}{l}\text { Time of antitoxin } \\
\text { administration }\end{array}$ & 5th day & 2nd day & 18th hour \\
\hline EEG & $\begin{array}{l}\text { Generalized slow wave } \\
\text { activity }\end{array}$ & No voltage supression & - \\
\hline ENMG & $\begin{array}{l}\text { Incremental response } \\
\text { with } 20 \mathrm{~Hz} \text { repetitive } \\
\text { stimulation }\end{array}$ & $\begin{array}{l}\text { Incremental response } \\
\text { with } 50 \mathrm{~Hz} \text { repetitive } \\
\text { stimulation }\end{array}$ & $\begin{array}{l}\text { Incremental response } \\
\text { with repetitive } \\
\text { stimulation }\end{array}$ \\
\hline $\begin{array}{l}\text { Duration of } \\
\text { invasive mechanical } \\
\text { ventilation }\end{array}$ & 8 days & 20 days & 15 days \\
\hline $\begin{array}{l}\text { Duration of } \\
\text { hospitalization }\end{array}$ & 21 days (11 days in PICU) & $\begin{array}{l}50 \text { days } \\
(20 \text { days in PICU) }\end{array}$ & $\begin{array}{l}63 \text { days } \\
\text { ( } 15 \text { days in PICU) }\end{array}$ \\
\hline Type of toxin & Unknown & Type A & Type B \\
\hline Outcome & Excellent & Excellent & Excellent \\
\hline
\end{tabular}

EEG: electroencephalography, ENMG: electroneuromyography, PICU: pediatric intensive care unit

A similar male case reported from Taiwan (age 4 years 8 months) presented with loss of consciousness and respiratory distress and was intubated two hours after the emergence of clinical findings. Type A botulism toxin was demonstrated in the patient. Starting from the 2 nd day of admission, $250 \mathrm{ml}$ antitoxin treatment was administered for three days. On 7 th day spontaneous eye opening and face movements were seen and muscular power and DTR completely improved. On 10th day, patient was completely weaned from ventilator and was discharged from nasogastric tube on 27 th day. The patient was discharged on the 50 th day. ${ }^{14}$

In another case reported from Italy, an 11-yearold case with type B botulism underwent antitoxin treatment 18 hours after the onset of symptoms but the patient was intubated in spite of treatment and tracheostomy was opened on the 7 th day. Spontaneous movements returned on the 12th day and muscular power recovered extensively and communication started on the 14th day. The patient was weaned from the mechanical ventilator on the 15th day. After recovering completely in two months, the patient was discharged on 63rd day. ${ }^{10}$

Compared to these cases, our case improved very rapidly (5 hours) (Table I). The patient started to nod his head in response to questions on the third day of antitoxin treatment and was extubated on 8th day. He was discharged without any sequels 3 weeks after admission to the intensive care unit. The important point in our case is although the antitoxin was administered in the late period he responded to therapy rapidly and recovered in 3 weeks. (Table I).

In conclusion, in a patient presenting with symptoms of complete acute flaccid paralysis, if deep coma-mimicking symptoms are also present, botulism should be absolutely considered in differential diagnosis and in these patients antitoxin should be administered without delay. Botulism should be considered if any similar cases are seen in the family. Thus, it will be possible to discharge the patient earlier and to minimize complications associated with hospitalization.

\section{REFERENCES}

1. Sobel J. Botulism. Clin Infect Dis 2005; 41: 1167-1173.

2. Zhang JC, Sun L, Nie QH. Botulism, where are we now? Clin Toxicol (Phila) 2010; 48: 867-879.

3. Rosow LK, Strober JB. Infant botulism: Review and clinical update. Pediatr Neurol 2015; 52: 487-492.

4. Cherington M. Clinical spectrum of botulism. Muscle Nerve 1998; 21: 701-710. 
5. Dembek ZF, Smith LA, Rusnak JM. Botulism: Cause, effects, diagnosis, clinical and laboratory identification, and treatment modalities. Disaster Med Public Health Prep 2007; 1: 122-134.

6. Cherington M. Botulism: update and review. Semin Neurol 2004; 24: 155-163.

7. Carrillo-Marquez MA. Botulism. Pediatr Rev 2016; 37: 183-192.

8. Lange DJ, Brin MF, Warner CL, Fahn S, Lovelace RE. Distant effects of local injection of botulinum toxin. Muscle Nerve 1987; 10: 552-555.

9. Witoonpanich R, Vichayanrat E, Tantisiriwit K, et al. Survival analysis for respiratory failure in patients with food-borne botulism. Clin Toxicol (Phila) 2010; 48: 177-183.
10. Proverbio MR, Lamba M, Rossi A, Siani P. Early diagnosis and treatment in a child with foodborne botulism. Anaerobe 2016; 39: 189-192.

11. Sobel J. Diagnosis and treatment of botulism: A century later, clinical suspicion remains the cornerstone. Clin Infect Dis 2009; 48: 1674-1675.

12. Abgueguen P, Delbos V, Chennebault JM, et al. Nine cases of foodborne botulism type B in France and literature review. Eur J Clin Microbiol Infect Dis 2003; 22: 749-752.

13. Tacket CO, Shandera WX, Mann JM, Hargrett NT, Blake PA. Equine antitoxin use and other factors that predict outcome in type A foodborne botulism. Am J Med 1984; 76: 794-798.

14. Tsai HJ, Liang WC, Wang $\mathrm{CH}$, et al. Botulism with unusual rapid progression to complete paralysis in a child. Pediatr Neonatol 2015; 56: 425-428. 